\title{
CAD modeling and finite elemental design of indigenous knee brace
}

\author{
ASHISH VASWANI and SHARAD SHRIVASTAVA* \\ Department of Mechanical Engineering, BITS Pilani, Pilani 333 031, India \\ e-mail: sharad_shrivastava@pilani.bits-pilani.ac.in
}

MS received 22 September 2014; revised 17 April 2016; accepted 14 November 2018; published online 2 January 2019

\begin{abstract}
Walking problems aggravate with the advent of old age. One of the treatments for the walking problems is the use of knee brace. This paper reviews the existing designs of knee braces, assesses their merits and demerits and proposes an efficient, cost-effective, light-weight and attractive design of knee brace for Indian population. This paper models design of knee brace and analyzes stress shielding capacity of the knee brace using Finite elemental analysis. This paper discusses how this knee brace can overcome difficulties faced by other knee braces in market.
\end{abstract}

Keywords. Knee brace; components of knee brace; CAD modeling of knee brace; FEM design of indigenous knee brace; comparison of existing knee braces.

\section{Introduction}

This study describes the anatomy of the knee. It provides a brief description of anatomical parts of the knee and their function. Later it describes the problems of the knee and cites instances that might result in such problems. It provides an insight into gait cycle in humans. This study provides a foundation for the study of knee brace. It provides structural design of knee brace using CAD modeling software "Solidworks". It describes the parts and function of the knee orthosis. Finally, it analyses the stress on the knee and effects of knee brace to shield these stresses for peak loads occurring during daily activities. This project is unique as it utilizes indigenous low cost materials (table 1), analyses load bearing activities and has structural design uniquely suited for Indian population (short length in order to conceal knee brace underneath their clothes).

\section{Background information}

\subsection{Cause of walking problems}

Thirty percent of older adults living in the community have problems with walking that increases to $50 \%$ (approximately) in adults 85 years old and older [1]. However, problems with walking are not an inevitable consequence of older age. Rather, they reflect the overall effects of other conditions that become more common and severe with age. Common symptoms and conditions that contribute to walking disorders are such as arthritis and other joint diseases, diseases of the muscles or bones, circulation problems

*For correspondence in the legs, problems after orthopedic surgery or stroke, dementia, parkinson's disease, vision or balance problems.

\subsection{Evaluation of walking problems}

Complete physical examination may uncover problems with blood pressure, vision, limbs, joints, neck, or spine. Specific tests such as test of balance, coordination, strength, tone, sensation, body position, and gait. Blood tests can help eliminate certain disease conditions (e.g., anemia, problems with blood chemistry, etc.). X-rays may be needed to diagnose joint or bone problems. Other tests such as "Timed Up and Go" test [1] measures how long you take to get up from a chair, walk about 10 feet, turn around, and return to the chair.

\subsection{Existing treatment}

Many conditions causing walking problems are only partially treatable. Treatment provided leads to an improvement in function depending on the number, type, and severity of the conditions contributing to the walking problems. Treatment type includes medical therapy, surgery and orthoses. Medical therapy (combination of drug and physical therapy) improves some walking problems, such as those related to vitamin B12 deficiency, thyroid problems, knee arthritis, Parkinson's disease. Physical therapy for knee arthritis or stroke results in modest improvements. Surgery can also result in modest improvement for people who have spinal disc problems or arthritis of the knee or hip. Orthoses such as "lifts" (to correct for different leg lengths), ankle braces, and various shoe inserts or modifications can be used to reduce walking problems. In general, well-fitting walking shoes with low heels and relatively 
Table 1. Calculation for estimating cost of knee brace.

\begin{tabular}{|c|c|}
\hline $\begin{array}{l}\text { Vol of upper leg } \mathrm{cm}^{3}(\mathrm{~V}=(1 / 3) \\
* \pi * \mathrm{~h} *\left(\mathrm{r} 1^{\wedge} 2+\mathrm{r} 2^{\wedge} 2+(\mathrm{r} 1 *\right. \\
\mathrm{r} 2)))\end{array}$ & $\begin{array}{c}\text { Vol of lower leg } \mathrm{cm}^{3}(\mathrm{~V}=(1 / 3) \\
* \pi * \mathrm{~h} *\left(\mathrm{r} 1^{\wedge} 2+\mathrm{r} 2^{\wedge} 2+(\mathrm{r} 1 *\right. \\
\mathrm{r} 2)))\end{array}$ \\
\hline 2490 & 2806.29 \\
\hline Half Vol of upper leg $\mathrm{cm}^{3}$ & Half Vol of upper leg $\mathrm{cm}^{3}$ \\
\hline 1245 & 1403.145 \\
\hline Vol of upper leg with flap $\mathrm{cm}^{3}$ & Vol of lower leg with flap $\mathrm{cm}^{3}$ \\
\hline 3220 & 4130 \\
\hline $\begin{array}{l}\text { Half Vol of upper leg with flap } \\
\mathrm{cm}^{3}\end{array}$ & $\begin{array}{c}\text { Half of Vol of lower leg with } \\
\text { flap } \mathrm{cm}^{3}\end{array}$ \\
\hline 1610 & 2065 \\
\hline Vol of upper flap $\mathrm{cm}^{3}$ & Vol of lower flap $\mathrm{cm}^{3}$ \\
\hline 365 & 661.855 \\
\hline Density of nylon $\mathrm{g} / \mathrm{cm}^{3}$ & 1.14 \\
\hline Mass in $\mathrm{g}$ & 1170.6147 \\
\hline Cost of Nylon Rs per kg & 206 \\
\hline $\begin{array}{l}\text { Cost of (upper and lower) flaps } \\
\text { Rs }\end{array}$ & 241.1466282 \\
\hline $\begin{array}{l}\text { Vol of upper leg with flap and } \\
\text { brace } \mathrm{cm}^{3}\end{array}$ & $\begin{array}{c}\text { Vol of lower leg with flap and } \\
\text { brace } \mathrm{cm}^{3}\end{array}$ \\
\hline 7090 & 12000 \\
\hline $\begin{array}{l}\text { Half Vol of upper leg with flap } \\
\text { and brace } \mathrm{cm}^{3}\end{array}$ & $\begin{array}{c}\text { Half of Vol of lower leg with } \\
\text { flap and brace } \mathrm{cm}^{3}\end{array}$ \\
\hline 3545 & 6000 \\
\hline Vol of upper brace $\mathrm{cm}^{3}$ & Vol of lower brace $\mathrm{cm}^{3}$ \\
\hline 1935 & 3935 \\
\hline Density of neoprene $\mathrm{g} / \mathrm{cm}^{3}$ & 1.292 \\
\hline Mass in $\mathrm{g}$ & 7584.04 \\
\hline Cost of Neoprene Rs per kg & 350 \\
\hline $\begin{array}{l}\text { Cost of braces (upper and lower } \\
\text { braces) Rs }\end{array}$ & 2654.41 \\
\hline Cost of braces and flaps & 2895.56 \\
\hline Aluminium cost Rs per $\mathrm{kg}$ & 103.75 \\
\hline Aluminum hinges $(6 \times 100 \mathrm{~g})$ & 62.25 \\
\hline Total cost of materials will be & 2957.81 around Rs 3000 \\
\hline
\end{tabular}

thin, firm soles help maximize balance and improve walking. Other mobility aids such as canes and walkers can take the load off painful joints and increase balance and stability.

\subsection{Industry relevance}

Currently no pharmaceutical or health care industry in India is manufacturing or marketing indigenously fabricated knee orthoses. The existing treatment methods are too costly for the average citizen or have significant problems such as side-effects. Moreover, unaesthetic appearance makes these devices undesirable, though necessary.

\section{Proposed methodology}

The technical approach proposed for this study comprised of four major steps. The first step was to achieve thorough understanding of the anatomy of the knee, pharmacological treatment, bio-mechanics of the knee joint to identify the exact points of load bearing on the knee. The second step was to understand the advantages and disadvantages of the existing knee brace designs existing in the market through literature review. The third step was to design the prosthetic using CAD modeling software and to identify suitable choice of materials for the knee orthoses to be costeffective, light-weight and aesthetically appealing. The fourth step was to conduct finite elemental analysis of the proposed design using load bearing conditions of daily routine activities such as walking. These four steps have been discussed in detail in the following sections.

\section{Anatomical structure of knee}

Knee is a hinge joint made up two condyloid joints, one between each condyle of the femur and the corresponding meniscus, soft cartilage that serves to cushion the knee and helps it absorb shock during motion, and condyle of the tibia, and the knee cap (patella), which articulates on the end of the femur [2], modelled knee as tibiofemoral joint. Quadriceps femoris is muscle group of the leg, forming a large fleshy mass which covers the front and sides of the femur. Quadriceps act as powerful extensors of the knee joint. They are crucial in walking, running, jumping and squatting. The Quadriceps are required in stabilizing the patella and the knee joint during gait [3]. Hip extensors are muscles located in the anterior thigh. They are responsible to pull the knee down and backward. The Hip Extensors control the flexor movement at initial foot contact, initiating hip extension. A loss of extensor function will cause the trunk to lurch posteriorly at foot contact. Hamstrings are a group muscles located in the posterior of the thigh. They originate from the lower of the hip bone and extend to below the knee. As the hamstrings cross both hip and knee joint they are therefore involved in knee flexion and hip extension. During running, the hamstrings slow down the leg at the end of its forward swing and prevent the trunk from flexing at the hip joint. The triceps surae is a pair of muscles located in calf. These muscles both insert into the calcaneus, the bone of the heel of the human foot, and form the major part of calf muscle. The triceps surae contracts to induce flexion and stabilization of the ankle complex in the transverse plane. They are required primarily for movement in the sagittal plane and stabilization during locomotion (walking, running) [4]. The manner in which humans walk constitutes the Gait cycle. The Quadriceps and Hamstrings provide significant control of the knee during the Gait cycle. They move the knee and lock it so that it does not bend unnecessarily. The ligaments and bony anatomy of the knee joint provide a strong foundation to ensure stability.

Ligaments attach bones to bones and give strength and stability to the knee. The bones in the knee are connected together by the following ligaments: Articular Capsule, 
Anterior Cruciate, Ligamentum Patellae, Posterior Cruciate, Oblique Popliteal, Medial and Lateral Menisci, Tibial Collateral, Transverse, Fibular Collateral, Coronary. The knee joint may be injured due to number of reasons. Changing direction rapidly, landing from a jump in sports such as skiing and basketball may cause tears in the Anterior cruciate ligament [5]. Direct blow to the outside of the knee during football may result in Tibial Collateral ligament. Blow to the front of the knee may result in Posterior cruciate ligament injury. Knee injury could be as a result of torn meniscus due to twisting, cutting, pivoting, decelerating, being tackled or arthritis [6]. Vitamin D deficiency causes rickets that causes valgus deformity in which Tibia/fibula (not the joint itself) head away from midline, while in varus deformity, where Tibia/fibula (not the joint itself) head toward midline. Varus alignment causes the load-bearing axis to shift to the inside, causing more stress and force on the medial (inner) compartment of the knee stresses cartilage and ligaments.

\section{Literature review}

Knee problems occur in people of all ages especially elderly and women resulting in disorder, disease or injury such as arthritis. All these knee problems involve the treatment with medicines for symptomatic relief or surgery and it takes a minimum of 4 weeks to several months to recover. Knee orthoses are available which are used in all the types of knee problems. The types of knee brace are as follows.

(a) Prophylactic braces (preventive): They resist medial and lateral collateral ligament tears.

(b) Functional braces (recovery): They reduce the rotation of knee, support stability, increase agility and strength.

(c) Rehabilitation braces (immobilize post-surgery or injury): They limit the movement of the knee in both medial and lateral directions.

The cost of functional knee braces range from 20000 INR to 80000 INR [7]. The cost of knee orthoses that have locking feature (locking only in full knee extension) ranges from 80000 INR to 380000 [8].

\subsection{Problems with existing knee orthoses}

Use of lower limb orthoses is plagued by a high rejection rate as these are: bulky, hence distinctly visible, heavy, noisily locks only in full knee extension [8], costly and not suitable to Indian population. These factors are caused, to a great extent, by the fact that orthoses force the whole gait to be performed with the knee articulation in full extension. The problems with functional knee braces are that they require more effort, limit dexterity and might hurt other people [7]. To overcome these problems, there is a need for an orthoses which is not bulky, very sleek so that it is not distinctly visible but at the same time strong and flexible and is customized to Indian population, which can be worn inside dress and does not have components that would result in injuries to other people.

\section{CAD modeling}

The CAD modeling of knee brace was done using "Solidworks 2010". Knee ball was modeled as a sphere of $14.33 \mathrm{~cm}$ diameter. Frustrum of cones were modeled as upper and lower parts of leg with actual measurements. The upper leg was a frustrum with larger diameter as $15.44 \mathrm{~cm}$ and smaller diameter as $13.6 \mathrm{~cm}$ and length $15 \mathrm{~cm}$. The lower leg was a frustrum with larger diameter as $10.5 \mathrm{~cm}$ and smaller diameter as $8.12 \mathrm{~cm}$ and length $41 \mathrm{~cm}$. Socket was carved in these frustrums using the dome feature in "Solidworks 2010" such that both the frustrums and knee ball formed ball and socket joint similar to that in the knee. These frustrums were designed using the loft feature in "Solidworks 2010". Flaps of $1 \mathrm{~cm}$ thickness were placed on both these parts of leg in order to restrict motion of condyloid joints of knee [9]. They were modeled to fit over the respective legs and under the respective brace. Low cost materials such as Nylon (suitable in cold climate) or cotton (suitable in hot climate) could be used for the manufacture of these flaps. Upper and lower braces of $4 \mathrm{~cm}$ thickness were designed using shell feature and plane surface boundary cut feature in "Solidworks 2010". They were modeled to fit over the respective flaps. Simple low cost materials such as neoprene that is light weight, resilient could be used for fabrication of knee brace [9]. Hinges provided the degree of freedom to the knee brace similar to that of the knee. The hinges were designed in such a way as to provide locking mechanism [10], with protrusion on hinges as shown in figure 1 to the knee that could help people gain the lost locking function due to problems of the knee and ensure that does not bend unnecessarily. The hinges were joined to the braces by means of pins of $5 \mathrm{~mm}$ diameter. The hinges and pins should be made of aluminum so that it is light and would withstand more fatigue cycles [11]. The cost of the materials for the brace is Rs 3000 (calculations shown in table 1) approximately and it is low cost compared to the existing knee braces [7, 8]. Mechanical properties of material used in the knee brace are listed in table 2 The CAD model of knee brace is showed in figure 2 .

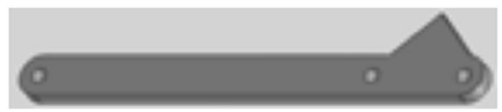

Figure 1. Hinge with locking mechanism. 
Table 2. Mechanical properties of material used in knee brace.

\begin{tabular}{|c|c|c|c|c|}
\hline $\begin{array}{l}\text { Material/ } \\
\text { properties }\end{array}$ & Neoprene & Bone & Aluminum & Nylon \\
\hline $\begin{array}{l}\text { Elastic } \\
\text { Modulus X } \\
\mathrm{N} / \mathrm{m}^{\wedge} 2\end{array}$ & 81500 & $1.4 \mathrm{e}+010$ & $7.1 \mathrm{e}+010$ & 8300000000 \\
\hline $\begin{array}{l}\text { Poisson Ratio } \\
\text { XY }\end{array}$ & 0.499 & 0.31 & 0.33 & 0.31 \\
\hline $\begin{array}{l}\text { Shear } \\
\text { Modulus } \\
\text { XY N/m^2 }\end{array}$ & 27185 & 150000000 & $2.7 \mathrm{e}+010$ & 3160000000 \\
\hline $\begin{array}{c}\text { Mass Density } \\
\mathrm{kg} / \mathrm{m}^{\wedge} 3\end{array}$ & 1292 & 1800 & 2770 & 1140 \\
\hline $\begin{array}{l}\text { Tensile } \\
\text { Ultimate } \\
\text { Strength } \mathrm{X} \\
\mathrm{N} / \mathrm{m}^{\wedge} 2\end{array}$ & 24000000 & - & $3.1 \mathrm{e}+08$ & 50000000 \\
\hline $\begin{array}{l}\text { Compressive } \\
\text { Ultimate } \\
\text { strength } \mathrm{X} \\
\mathrm{N} / \mathrm{m}^{\wedge} 2\end{array}$ & 24000000 & - & - & - \\
\hline $\begin{array}{c}\text { Tensile Yield } \\
\text { Strength } \\
\mathrm{N} / \mathrm{m}^{\wedge} 2\end{array}$ & 24000000 & 112500000 & $2.8 \mathrm{e}+08$ & 142559000 \\
\hline $\begin{array}{l}\text { Compressive } \\
\text { Yield } \\
\text { Strength } \\
\mathrm{N} / \mathrm{m}^{\wedge} 2\end{array}$ & 24000000 & 170000000 & $2.8 \mathrm{e}+08$ & - \\
\hline
\end{tabular}

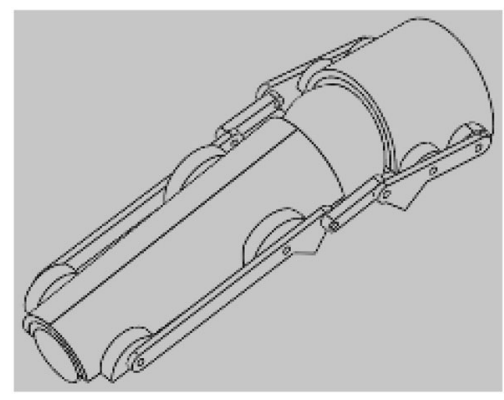

Figure 2. CAD model of knee brace.

\section{Evaluation of stress in knee with finite elemental analysis}

For the purpose of this study we have used joint moments obtained using a dynamometer for different joint angles of the same subject [12]. The subject in this paper had the weight of $80 \mathrm{~kg}$ and height of $183 \mathrm{~cm}$. The subject information in this paper tallies with the subject information for our study. The aim of our study was to evaluate the stresses at hip, ankle and knee after using the knee brace and comparing it with the peak stresses obtained from [13] during daily activities with the help of finite elemental analysis. Finite element method uses the general formula given in Eq. (1).

$$
\begin{aligned}
\text { Force } \left._{\text {matrix }}\right] & =[\text { stiffness matrix }] *[\text { displacement matrix }] \\
{[\mathrm{F}] } & =[\mathrm{K}] *[\mathrm{u}]
\end{aligned}
$$

The upper part of leg, lower part of leg, upper flap, lower flap, upper brace, lower part of brace, knee joint are the elements considered for this analysis. The elements are varying in cross section. The equivalent stiffness, $\mathrm{K}_{\mathrm{eq}}$ of the elements is linearly dependent on area. So the element needs to be divided into smaller parts with uniform cross sectional area joined to two or more elements at nodes. In ANSYS it is divided into 8162 program controlled elements and 28951 nodes as shown in figure 3.

The brace allows both linear and rotational degrees of freedom allowed for the knee. The equivalent stiffness matrix for force as well as torque needs to be evaluated. The stiffness for force matrix is given by Eq. (2) and the stiffness of torsion matrix is given by Eq. (3).

$$
\mathrm{K}_{\mathrm{eq}}=\mathrm{AL} / \mathrm{E}
$$

A is the cross sectional area of the element,

$\mathrm{L}$ is the length of the element,

and $\mathrm{E}$ is Young's modulus of elasticity of the element.

$$
\mathrm{K}_{\mathrm{eq}}=\mathrm{JG} / \mathrm{L} \text { (Torsion) }
$$

$\mathrm{J}$ is the polar moment of inertia of the element,

$\mathrm{L}$ is the length of the element,

$\mathrm{G}$ is the shear modulus of the element.

This study uses the same forces and moments on the hip, ankle and knee as in [13] $\left(\mathrm{M}_{\text {hip }}=136 \mathrm{Nm}, \mathrm{M}_{\text {knee }}=97 \mathrm{Nm}\right.$, $\mathrm{M}_{\text {ankle }}=-20 \mathrm{Nm}, \quad \mathrm{F}_{\text {triceps }} \quad$ surae $=0.4 \mathrm{kN}, \quad \mathrm{F}_{\text {quadriceps }}=$

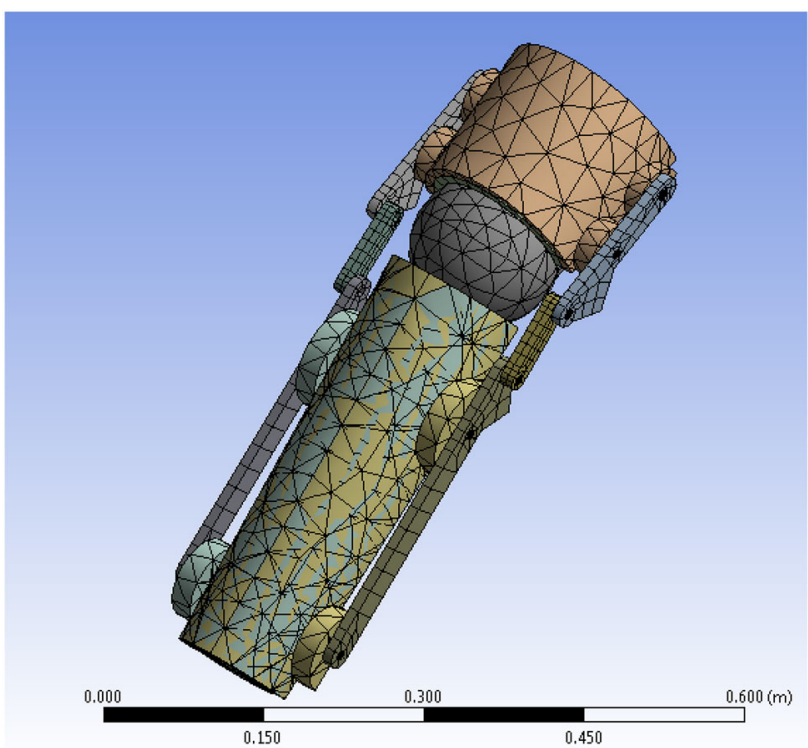

Figure 3. Elements and nodes in the knee brace. 


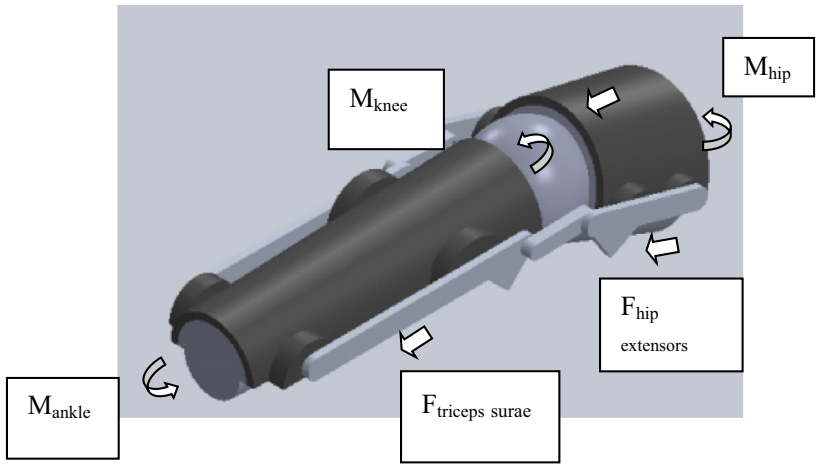

Figure 4. Forces and moments on the lower leg, upper leg and knee.

$3.4 \mathrm{kN}, F_{\text {hip }}$ extensors $\left.=2.4 \mathrm{kN}\right)$. The force and moment matrix for the knee brace is given by Eq. (4).

$$
\left|\begin{array}{c|}
\text { Fhipextensors } \\
0 \\
\text { Fquadriceps } \\
0 \\
\text { Ftricepssurae }
\end{array}\right| \quad\left|\begin{array}{c}
\text { Mhip } \\
0 \\
\text { Mknee } \\
0 \\
\text { Mankle }
\end{array}\right|
$$

The force and moment on the knee brace are shown in figure 4.

Finite elemental analysis was conducted using force, moment and stiffness matrices along with boundary conditions (such as hip joint is fixed) to evaluate displacement matrix, [u] given by Eq. (5).

$$
[u]=[F] *[K]^{-1}
$$

$[\mathrm{u}]=$ Displacement matrix for nodes

$[\mathrm{F}]=$ Force matrix for nodes

$[\mathrm{K}]^{-1}=$ Inverse of stiffness matrix

The strain can be determined Eq. (6). The von mises stresses $(\sigma)$ in the knee, upper brace, lower brace, upper leg, lower leg can be evaluated by Eq. (7). The parameters used in ANSYS to evaluate von Mises stress and principal strain have been listed in table 2 .

$$
\varepsilon=\left(\mathrm{u}_{\mathrm{m}}-\mathrm{u}_{\mathrm{n}}\right) / \mathrm{L}
$$

$\mathrm{u}_{\mathrm{m}}$ and $\mathrm{u}_{\mathrm{n}}$ are the displacements of nodes of the element, $\mathrm{L}$ is the length of the element.

$$
\sigma=\mathrm{E} * \varepsilon
$$

$\sigma$ is the von Mises stress in the knee, upper brace, lower brace, upper leg, lower leg,

$\varepsilon$ is the strain of the element,

$\mathrm{E}$ is the Young's Modulus of Elasticity of the element.

\section{Results and discussion}

The stresses and strains (shown in figures 5 and 6, respectively) assessed on the knee brace and knee were calculated using static structural analysis in ANSYS. The materials used were bone for knee, upper and lower leg, nylon for the upper and lower flaps, neoprene for upper and
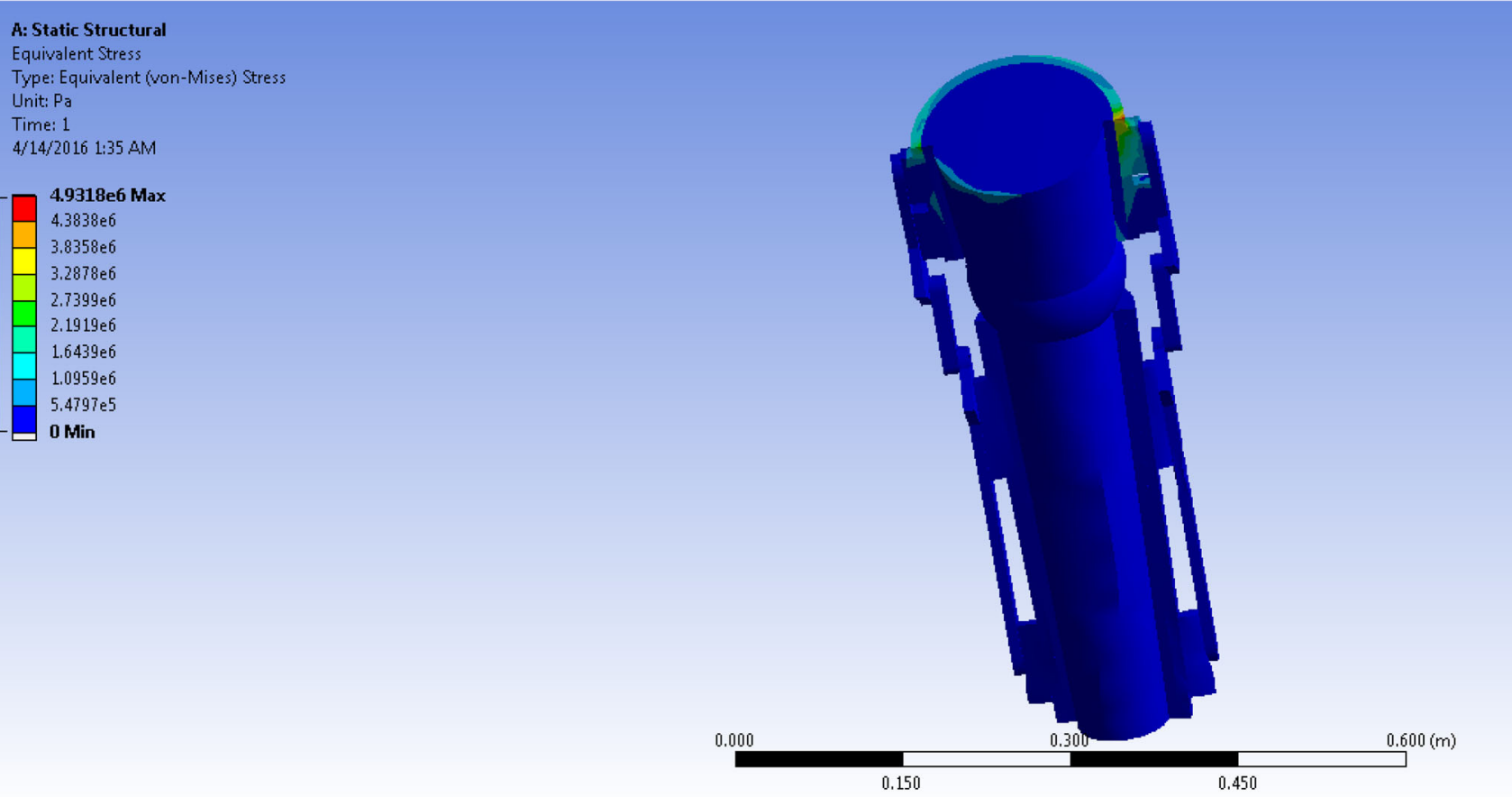

Figure 5. Stress distribution in the knee brace. 


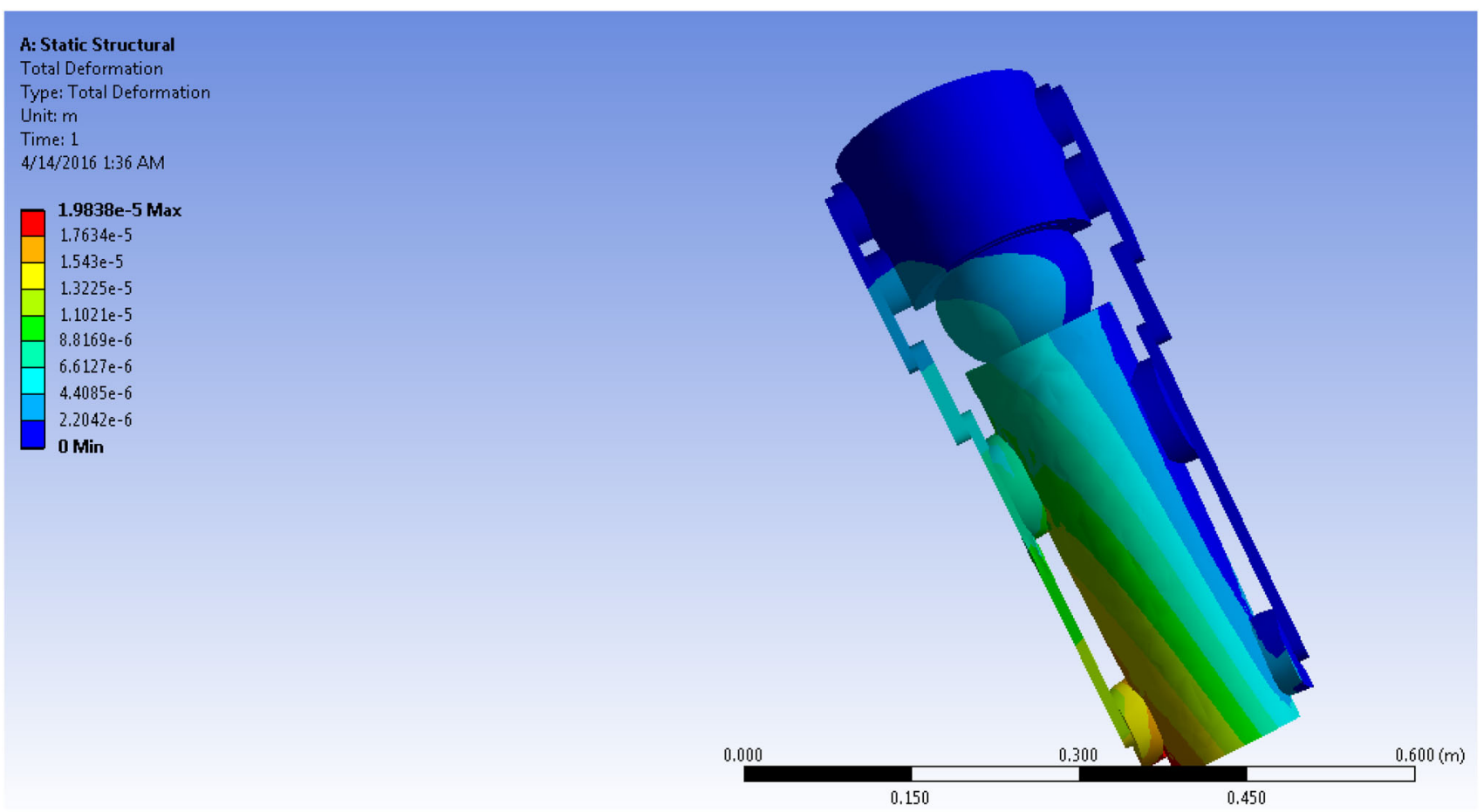

Figure 6. Strain distribution in the knee brace.

lower brace, aluminum for hinges and pins. Nonlinear controls were used for analysis.

It can be seen from results that von Mises stress of $0.5 \mathrm{MPa}$ which is much less than maximum tibiofemoral stress of $5 \mathrm{MPa}$ on the knee without knee brace in the condition of walking without pain [14], thus well within acceptable limits of the knee. The stress on the knee brace is $4 \mathrm{MPa}$ while that on knee is $0.5 \mathrm{MPa}$ that gives a clear indication that knee brace is effective in shielding stress from the knee. Thus, the present study provides a simple knee brace prototype to shield knee from stress and prevent relative motion as there is a strain of only 6 microns that would lead to speedy recovery and help in ameliorating the pain.

This knee brace overcomes problem of bulkiness, thus does not limit dexterity and also does not require extra effort. None of components except aluminum hinges can hurt as other components are made of neoprene and nylon. The aluminum hinges can be covered by neoprene casing to prevent injuries.

\section{Applications}

This device would improve 'Quality of Life' (QOL) of the elderly [15]. It would supplement therapy for arthritis patients and patients on surgical rehabilitation. It has a potential of auxiliary utility for the paraplegic patients. It would help in prevention of contractures and immobilization-related joint damage and reduced muscular atrophy. It could also stimulate unaffected areas of the brain to take over functions such as motor relearning and cortical reorganization in cases of patients suffering from diseases affecting the CNS. Therefore, orthosis helps the patient reintegrate both socially and professionally.

\section{Conclusion}

This study provides a CAD model for simple knee brace prototype from low cost materials such as neoprene, nylon and aluminum to shield knee from stress and relative motion that would lead to speedy recovery and help in ameliorating the pain.

\section{Acknowledgements}

The first author (Ashish Vaswani) expresses his gratitude to his guide Dr Sharad Shrivastava for motivating to work in the interesting field of biomechanics. He would also like to express his gratitude to Dr Arun Jalan for helping to understand design concepts in this project and friends Mr Mohit, Mr Rahul, Mr Rohit and Mr Amrit for helping to understand software usage. Solidworks 2010 and ANSYS software came handy for bringing ideas into virtual reality. Ashish Vaswani thanks Mechanical Engineering Department and BITS Pilani for giving an excellent opportunity to realize scientific aptitude through the channel of thesis [16]. 


\section{References}

[1] Salzman B 2010 Gait and balance disorders in older adults. Am. Fam. Physician 82: 61-68

[2] Gray H 1918 Anatomy of the human body. Lea \& Febiger, Philadelphia. Bartleby.com, 2000, 7b The Knee-joint

[3] Kisner C and Colby L A 2007 The ankle and foot. Therapeutic exercise-Foundation and Techniques, 5th edition. New Delhi: Jaypee Brothers, 776-777

[4] Gray H 1918 Anatomy of the human body. Lea \& Febiger, 8, b, The Muscles and Fasciae of the Thigh, c, The Muscles and Fasciae of the Leg, d, The Fasciae Around the Ankle. Twentieth edn. Philadelphia and New York: Lea and Febiger, 424-431

[5] Larsen E, Jensen P K and Jensen P R 1999 Long-term outcome of knee and ankle injuries in elite football. Scand. J. Med. Sci. Sports 9: 285-289

[6] Rand J A 1985 Arthroscopic management of degenerative meniscus tears in patients with degenerative arthritis. Arthrosc. J. Arthrosc. Relat. Surg. 1: 253-258

[7] Paluska S A and McKeag D B 2000 Knee braces: current evidence and clinical recommendations for their use. Am. Fam. Phys. 61: 411-418

[8] Kofman J 2009 Engineering design review of stance-control knee-ankle-foot orthoses. J. Rehabil. Res. Dev. 46: 257
[9] Fatool W and Ferraro R J 1989 U.S. Patent No. 4,870,956. Washington, DC: U.S. Patent and Trademark Office

[10] France E P, Paulos L E and Ellingson R L 1994 U.S. Patent No. 5,277,697. Washington, DC: U.S. Patent and Trademark Office

[11] Martin K 1984 U.S. Patent No. 4,489,718. Washington, DC: U.S. Patent and Trademark Office

[12] Fukunaga T, Roy R.R, Shellock F G, Hodgson J A, Day M K, Lee P L and Edgerton V R 1992 Physiological crosssectional area of human leg muscles based on magnetic resonance imaging. J. Orthop. Res. 10: 926-934

[13] Thorpe S K, Li Y, Crompton R H and Alexander R M 1998 Stresses in human leg muscles in running and jumping determined by force plate analysis and from published magnetic resonance images. J. Exper. Biol. 201: 63-70

[14] Nagura T, Matsumoto H, Kiriyama Y, Chaudhari A and Andriacchi T P 2006 Tibiofemoral joint contact force in deep knee flexion and its consideration in knee osteoarthritis and joint replacement. J. Appl. Biomech. 22: 305

[15] Brouwer R W, Van Raaij T M, Verhaar J A N, Coene L N J E M and Bierma-Zeinstra S M A 2006 Brace treatment for osteoarthritis of the knee: a prospective randomized multicenter trial. Osteoarthr. Cartil. 14: 777-783

[16] Vaswani A 2013 CAD Modeling and Finite Elemental Design of Indigenous Knee Brace. BE (Hons) Mechanical Engineering, BITS Pilani, Pilani 